\title{
The effect of wet-cupping on the severity of migraine headaches: Randomized controlled clinical trial
}

\author{
Mohammad Zarei $^{1 \oplus}$, Amir Tabatabaee ${ }^{2, *}$, Mostafa Roshan Ravan $^{3}$
}

${ }^{1}$ Faculty Member of Natural Products and Medicinal Plants Research Center, North Khorasan University of Medical Sciences, Bojnurd, Iran

${ }^{2}$ Nursing Department, Nursing Faculty, Quchan Branch, Islamic Azad University, Quchan, Iran, Mashhad Road, Quchan, Iran, No 9471946316

${ }^{3}$ Nursing Department, Faculty of Nursing and Midwifery, North Khorasan University of Medical Sciences, Bojnurd, Iran

\section{Correspondence}

Amir Tabatabaee, Nursing Department, Nursing Faculty, Quchan Branch, Islamic Azad University, Quchan, Iran, Mashhad Road, Quchan, Iran, No 9471946316

Email: amir.ta1351@gmail.com

History

- Received: Dec 01, 2018

- Accepted: Jan 21, 2019

- Published: Feb 20, 2019

DOI :

https://doi.org/10.15419/bmrat.v6i2.52

\section{Check for updates}

\section{Copyright}

(c) Biomedpress. This is an openaccess article distributed under the terms of the Creative Commons Attribution 4.0 International license.

\begin{abstract}
Introduction: This study aimed to determine the effect of wet-cupping on pain intensity in patients with migraines. Method: 132 patients were diagnosed with migraines. Pain intensity was evaluated based on the visual analogue scale. After homogenizing the data, patients were randomly divided into two (wet-cupping and control) groups. Paired t-test, Kruskal-Wallis and Mann-Whitney tests were used to analyze the data. Results: The mean of pain intensity of wetcupping (7.61 \pm 1.29$)$ and control (7.22 \pm 1.21$)$ before the intervention showed no significant difference $(p=0.401)$. There was a significant difference between the mean of pain relief intensity of wet-cupping (2.4 \pm 1.9$)$ and control $(0.6 \pm 0.8)$ groups before and after interventions $(p<0.001)$. Conclusion: Wet-cupping is an effective tool to treat migraine headaches. Trial registration: Current Controlled Trials IRCT201110314495N2

Key words: Complementary medicine, Migraine headache, Wet-cupping
\end{abstract}

\section{INTRODUCTION}

Pain is an unpleasant sensory and emotional experience associated with actual or potential tissue damage and is the most common reason for visits to health centers ${ }^{1}$. People with pain often express unwillingness to frequent movement, which leads to a decrease in social interactions and lack of participation in daily activities that ultimately results in frustration, distrust and social isolation ${ }^{2}$.

Chronic pain can have different causes, and $2 \%$ of people are suffering chronic pain from migraine headaches ${ }^{3}$. Migraine is a chronic and episodic neurological disorder characterized by periodic and recurrent severe headache, which lasts from 4 to 72 hours in adults. According to the studies conducted in 50 countries, the prevalence of this disease was $6 \%$ in men and $18 \%$ in women ${ }^{4}$. About $66 \%$ of the sufferers had a family history of migraine, and in the intervals between throbbing, pounding, or pulsating migraine attacks, there were also periods without any headaches ${ }^{5}$.

Pain control is important in patients with migraine. American Pain Society considers pain as the fifth vital sign, and the control and relief of pain by pharmaceutical and non-pharmaceutical methods is one of the major challenges for the health care team members ${ }^{4}$. Due to the side effects of drugs, nowadays, non-pharmaceutical pain relief methods have been developed ${ }^{6}$. The non-pharmaceutical interventions are called complementary or alternative therapies ${ }^{7}$
, which include temperament modifications, therapeutic touch, hypnosis, homeopathy, aromatherapy, acupuncture, cupping and so on ${ }^{8}$.

Complementary Medicine is a low-risk, cost-effective and simple method with limited side effects and its application is increasing in a number of treatment and care centers throughout the world ${ }^{9}$. By estimation, about one-third of people use some kinds of these treatments for common diseases such as backache, headaches, anxiety and depression throughout their lifetime ${ }^{8}$. In Iran, there are no general statistics regarding the use of traditional medicine, but the results of a study conducted in Tehran indicated that about half of the population of Tehran, have used at least one of these treatments of Traditional Complementary Medicine ${ }^{10}$.

One of the traditional treatment methods is "cupping", which is performed to prevent and treat various diseases ${ }^{11-15}$. Cupping is an important principle of traditional medicine in Asia, which supports body tissues to release toxins and excreta to guarantee the health of individuals. Avicenna in the book of "The Canon of Medicine" has prescribed cupping for some diseases ${ }^{14}$. Cupping helps to regulate blood circulation and lymphatic flow ${ }^{16}$. It is claimed that cupping can improve the performance of connective tissues, return blood flow towards skin and muscles, decrease pain and blood pressure, and enhance the modulation in the immune, nervous and hormonal systems ${ }^{17}$. Zarei and colleagues reported a decrease in blood 
pressure in patients who underwent cupping therapy ${ }^{18}$. Today, cupping is used as an alternative and complementary therapy, especially in patients suffering from pain syndromes ${ }^{19}$. Dorina and colleagues reported that shoulder pain and fatigue in nurses reduced after two weeks of cupping if applied twice a week $^{20}$. According to Tabatabaee and colleagues, the average pain intensity score in migraine patients decreased after cupping ${ }^{21,22}$. However, the precise effects of cupping in pain relief remain unknown, and many doctors are skeptical about its value ${ }^{17}$.

Considering that complementary and traditional medicines have found become more popular in Iran in recent years, researchers sought to examine the results and effects of wet-cupping on migraine headache to direct the attention of patients and medical staff towards non-pharmaceutical treatments such as cupping for the lower cost and less side effects. This study aimed to determine the effects of cupping in reducing pain intensity in patients with migraines.

\section{METHODS}

This controlled clinical trial was carried out on patients with migraines, who had visited the Official Center of Traditional Medicine of Quchan in 2012. Considering the previous studies and comparison of the average pain intensity scores of patients in the first and third sessions of the preliminary study, with the accuracy of 0.5 and statistical power of $80 \%$ and confidence level of $95 \%$, the sample size was estimated as 102 patients. Given the possibility of sample size reduction, 132 patients were selected and studied by the convenience sampling method. Principles of medical ethics were observed at all stages of the project. Patients were included in the study with full consents and without coercion. The information obtained from patients were completely confidential. In order to control intervening variables, patients who were eligible for the study (residing in Quchan) must have an approval of the diagnosis of migraine headache by specialist physicians. Patients must not have any coexisting disease history such as low blood pressure, anemia or other contraindications to use cupping, and must have the ability to cooperate with a full consent to use therapeutic method. Eligible patients must be free of stressful events during the 6-month period prior to the study, they must not be in pregnancy and not addicted to drugs and alcohol. Patients were matched for gender, age and dose of drugs. Using random sampling method, patients were divided into two groups of control and cupping treatment. Patients that had experienced stressful events or had used other complementary methods during the research were excluded from the study.

To collect data, a two-part questionnaire was used, which consisted of demographic characteristics (age, sex, marital status, education level, type and dose of drugs), the types of headache and a pain record form. The reliability of the tool was verified by test-retest method in the intervals of 14 days $(r=0 / 85)$. The reliability and validity of VAS was reviewed and verified in various studies ${ }^{17,23}$.

After the study plan was approved by the Medical Ethics Committee of the University and the registration in the Iranian Registry of Clinical Trials (IRCT201110314495N2) completed, sampling and grouping were conducted. In the cupping group, after completing the questionnaire, an interview and examinations, three stages of general cupping were performed in a clinic with every two weeks by 2 cuppers. In the second and the third times of cupping, only the intensity of pain before and after cupping was measured and recorded. For all patients, at the beginning of cupping, the intended place on the skin was sterilized by betadine. After the first cupping, skin scratches are created with a sterile surgical blade in eleven rows of three scatches with the same depth and immediately, the second cup was placed at the same place for bloodletting for one minute. The second cup was then removed and blood was let out for another time, and the cup was placed again for suction. At the end of three stages of bloodletting, after cleaning the area with sterile cotton, sterile gauze dressing was performed. The numbers of cupping therapy depends on the patients. Cupping was perform every 2 weeks. The control group only used medication and no intervention was applied. Their questionnaire was completed through interview and examination. At the end of week 6 , the pain intensity was measured in two groups.

The paired t-test was used to determine the relationship between pain and individual characteristics. To compare the pain intensity before intervention between groups, Kruskal-Wallis test was employed and Mann-Whitney test was used to compare the differences in the average pain intensity scores before and after the intervention. All statistical tests were performed in SPSS19 software.

\section{RESULTS}

In this study, 70 subjects $(53.03 \%)$ were female and $68(51.5 \%)$ subjects were in the age of $31-45$ years. The average age of all samples was $34.7 \pm 10.2$ years. 48 subjects (36.4\%) were illiterate, making the highest frequency among the samples and 38 subjects (28.8\%) 
were highly educated. 90 subjects $(68.2 \%)$ had bilateral pain patterns and 89 subjects $(67.4 \%)$ had severe pain before the intervention (5-7). None of the subjects had no pain or mild pain. Two patients $(1.5 \%)$ suffered from moderate pain (3-4) and 43 (32.6\%) patients suffered from intolerable pain (8-10). The pain severity of the majority of the subjects was unbearable before the cupping therapy, however, after the first two sessions, the average pain was $48.9 \%$, and after 6 weeks the average pain severity was indicated at $61.7 \%$.

$88 \%$ of the samples used chemical painkillers as the main treatment option for relieving headaches. During the study period, the dose and frequency of the medication were not changed. $77 / 4 \%$ of the samples consumed painkillers only once a day at the time of pain incidence.

Pain intensity before the interventions had no significant relationship with the occupations, marital status, and levels of education and occupation $(\mathrm{P}>0.05)$. The average pain intensity score showed no significant difference in cupping $(7.61 \pm 1.29)$ and control (7.22 \pm 1.21$)$ groups before the interventions $(\mathrm{P}=0.401)$. The average pain relief intensity scores in two groups of cupping $(2.4 \pm 1.9)$ and control $(0.6 \pm 0.8)$ before and after the interventions were significantly different $(\mathrm{P}<0.001)$. Paired comparison of average pain intensity scores before and after the intervention in the groups also indicated significant differences in two groups $(\mathrm{P}<0.05)$.

\section{DISCUSSION}

The aim of this study was to determine the effects of cupping on pain intensity in patients with migraine. $88 \%$ of subjects had used chemical medications for pain relief before the cupping. The dose of medications did not change during the study and the results showed that cupping therapy significantly decreased the intensity of migraine pain in patients, and at the same time, exposing no side effects. In most of the clinical trials conducted to evaluate the effect of cupping on the relief of pain, there were either methodological problems or problems related to the report of the results of this therapy, which indicates the need for further studies in this field ${ }^{17}$. There was no statistically significant relationship between the reduction in pain intensity and other factors such as genders, education levels and marital status, which is consistent with previous studies ${ }^{21,22}$.

There was a statistically significant difference between the average pain intensity scores in the cupping group at the beginning and the end of the study, similarly to the average pain intensity scores between cuppings and control groups at the beginning and end of the study. These results are consistent with the research of Ahmadi that cupping decreased severe migraine headaches by 66 percent and the days of headache per month reduced by 12.6 percent $^{24}$. It was suggested that a complete course of cupping is more effective than one-time application ${ }^{24}$. In the present study, a complete course of cupping was performed. Kheyrandish also emphasized the positive effects of cupping on pain relief when assessing the effectiveness of cupping therapy for backache ${ }^{14}$. Farahani et al. showed that cupping expressed more short-term clinical benefits and fewer side effects compared to usual cares ${ }^{25}$. The mechanism of cupping therapy is unknown, however, some experts suggested that the location and the spots of cupping on the skin result in an increase in temperature or homeostasis, which impacts the immune system to create therapeutic effects ${ }^{12,26}$.

Cupping is an old traditional therapeutic method, however, it is a new subject for scientific studies. Researchers in this study were confronted with uncontrollable constraints, including different pain thresholds in different individuals and different mental conditions of subjects during the interviews. The results of this study may not be generalized due to the small sample size; therefore, further study is recommended with more patients, longer study periods and in different diseases.

Due to the high rates of using complementary medicine, it is necessary to plan for medical training and competent groups to provide the traditional and complementary medicine services more efficiently and securely ${ }^{27}$. In order to relive the pain of patients, most doctors and nurses use pain killers, which increases the medical cost and the risk of side effects. Cupping is an inexpensive method that has no side effects and can be considered for pain relief. More randomized controlled studies are required to validate these results and to compare the effects of cupping therapy with placebo or other standard medical cares.

\section{CONCLUSIONS}

Base on the findings of this research, it is suggested that cupping therapy may have a relieving effect in migraine patients and this treatment and can be considered as an effective, low cost and applicable method that are accepted by patients.

\section{COMPETING INTERESTS}

The authors declare no conflict of interests. 


\section{AUTHORS' CONTRIBUTIONS}

M.Z. and A.T. contributed to the conceptualization and design of the study, the acquisition, analysis and interpretation of data. M.Z. and M.R. were for drafting the article and revising the article critically for important intellectual content. All authors read and approved the final manuscript.

\section{ACKNOWLEDGMENTS}

This article was derived from a research project approved by the Islamic Azad University of Quchan, which was conducted with the financial support of this university. The researchers would like to express their gratitude to the University Research Council and all patients, who participated in this study.

\section{REFERENCES}

1. Brunner LS, Smeltzer SC, Bare BG, Hinkle JL. Brunner \& Suddarth's textbook of medical surgical nursing. New York: Wolters Kluwer Health; 2014.

2. Monahan FD, Sands JK, Neighbors M, Marek JF, Green-Nigro CJ. Phipps medical surgical nursing, health and illness perspectives. New York: Lippincott Williams \& Wilkins; 2007.

3. LoBiondo-Wood G, Habber J. Nursing research critical appraisal \& utilization. St. Louis: Mosby; 2007.

4. Black JM, Hawks JH. Medical-surgical nursing: clinical management for positive outcomes. St. Louis: Saunders/Elsevier. 2009 .

5. Holland S, Silberstein SD, Freitag F, Dodick DW, Argoff C, Ashman $E$, et al. Evidence-based guideline update: NSAIDs and other complementary treatments for episodic migraine prevention in adults: report of the Quality Standards Subcommittee of the American Academy of Neurology and the American Headache Society. Neurology. 2012;78(17):1346-53. Available from: 10.1212/WNL.0b013e3182535d0c.

6. Raggi A, Leonardi M, Bussone G, D'Amico D. A 3-month analysis of disability, quality of life, and disease course in patients with migraine. Headache. 2013;53(2):297-309. Available from: $10.1111 / j .1526-4610.2012 .02279 . x$.

7. Shmueli A, Shuval J. Are users of complementary and alternative medicine sicker than non-users? Evid Based Complement Alternat Med. 2007;4(2):251-5. Available from: 10.1093/ecam/ nel076.

8. Mirzai V, Saiadi AR, Heydarinasabm M. Knowledge and attitude of Rafsanjani physicians about complementary and alternative medicine. Zahedan J Res Med Sci. 2011;13:20-4.

9. Harlow C. A critical analysis of healing touch for depression and anxiety; 2013. University of Arizona.

10. Banihashemi SAT, Fard HA, Hagdoost AA, Beraghmadi M, Hosseini NM. Epidemiology of applying traditional and complementary medicine in Tehran. Payesh J. 2008;7:355-62.
11. Shirazi HMA. Sharhi bar kholasat-olhekmah [in Persian]; 2009. Hil, Tehran.

12. Jorjani SE. Zakhireh kharazmshahi [in Persian]. Publications of the Academy of Medical Sciences of the Islamic Republic of Iran, Tehran. 2003;1.

13. Jorjani SE. Zakhireh kharazmshahi [in Persian]. Publications of the Academy of Medical Sciences of the Islamic Republic of Iran, Tehran. 2003;2.

14. Avicenna H. The Canon. Tehran: Soroosh Publications; 2010.

15. Chirali IZ. Cupping therapy: Traditional Chinese medicine. London: Churchill Livingstone; 2007.

16. Matin A. Traditional Medicine [in Persian]; 2001. Islamic culture and thought, Tehran.

17. Lee MS, Kim Jl, Ernst E. Is cupping an effective treatment? An overview of systematic reviews. J Acupunct Meridian Stud. 2011;4(1):1-4. Available from: 10.1016/S2005-2901(11)60001 0.

18. Zarei $\mathrm{M}, \mathrm{Hejazi} \mathrm{SH}$, Javadi SA, Farahani $\mathrm{H}$. The efficacy of wet cupping in the treatment of hypertension. ARYA Atheroscler J. 2012;8:145-8.

19. Hubera R, Emerich M. Braeunig, Cupping- is it reproducible? Experiments about factors determining the vacuum. Compl Ther Med. 2011;19(2):78-83. Available from: 10.1016/j.ctim. 2010.12.006.

20. Sohn D, Yoon HM, Jung HM. Jung Effects of dry cupping therapy on shoulder pain and fatigue in nurses. J Pharmacopuncture. 2011;14(2):25-36. Available from: 10.3831/KPI.2011.14 2.025 .

21. Tabatabaee A, Zarei M, Mohammadpour A, Javadi SA, Bidak AA. The effects of wetcupping on intensity of headache in migraine sufferers. Jundishapur J Chron Dis Care. 2014;3(2):112.

22. Tabatabaee A, Zarei M, Mohammadpour A. Comparing the effect of wet-cupping and temperament reform on the severity of migraine headaches. Quarterly of the Horizon of Medical Sciences. 2014;20(1):43-8.

23. Ferreira-Valente MA, Pais-Ribeiro JL, Jensen MP. Validity of four pain intensity rating scales. Pain. 2011;152(10):2399-404 Available from: 10.1016/j.pain.2011.07.005.

24. Ahmadi A, Schwebel DC, Rezaei M. The efficacy of wetcupping in the treatment of tension and migraine headache. Am J Chin Med. 2008;36(1):37-44. Available from: 10.1142/ S0192415X08005564.

25. Farhadi K, Schwebel DC, Saeb M, Choubsaz M, Mohammadi R, Ahmadi A. The effectiveness of wet-cupping for nonspecific low back pain in Iran: a randomized controlled trial. Complement Ther Med. 2009;17(1):9-15. Available from: 10.1016/j. ctim.2008.05.003.

26. Cao H, Li X, Liu J. An updated review of the efficacy of cupping therapy. PLoS One. 2012;7(2):e31793. Available from: 10.1371/ journal.pone.0031793.

27. Hassanzadeh M, Kiani F, Bouya $S, M$ Z. Comparing the effects of relaxation technique and inhalation aromatherapy on fatigue in patients undergoing hemodialysis. Complementary therapies in clinical practice. 2018;31:210-214. Available from: 10.1016/j.ctcp.2018.02.019. 